\title{
Author Correction: OsFTIP7 determines auxin-mediated anther dehiscence in rice
}

Shiyong Song, Ying Chen, Lu Liu, Yen How Benjamin See, Chuanzao Mao, Yinbo Gan and Hao Yu (D)

Correction to: Nature Plants https://doi.org/10.1038/s41477-018-0175-0, published online 18 June 2018.

In the version of this Article originally published, an incorrect immunoblot was used in the left, middle panel of Fig. 6a, which describes $\alpha$-tubulin expression in whole-cell extracts, and should have appeared as shown here. This panel, and the corresponding quantitative result shown in Supplementary Fig. 11e, have now been corrected in the Article. This does not affect the results or conclusions of this work.

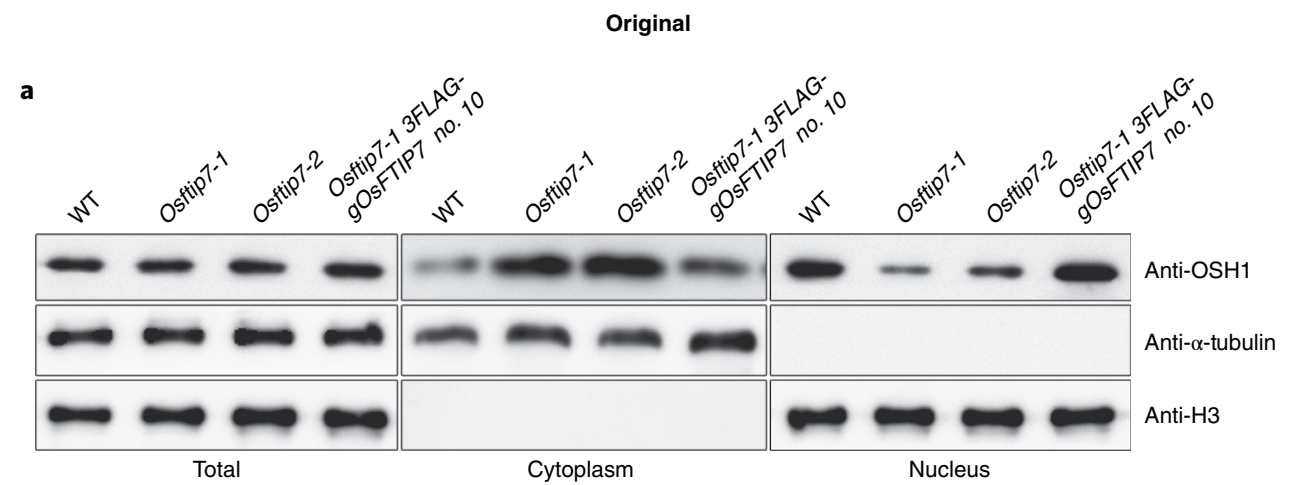

Corrected

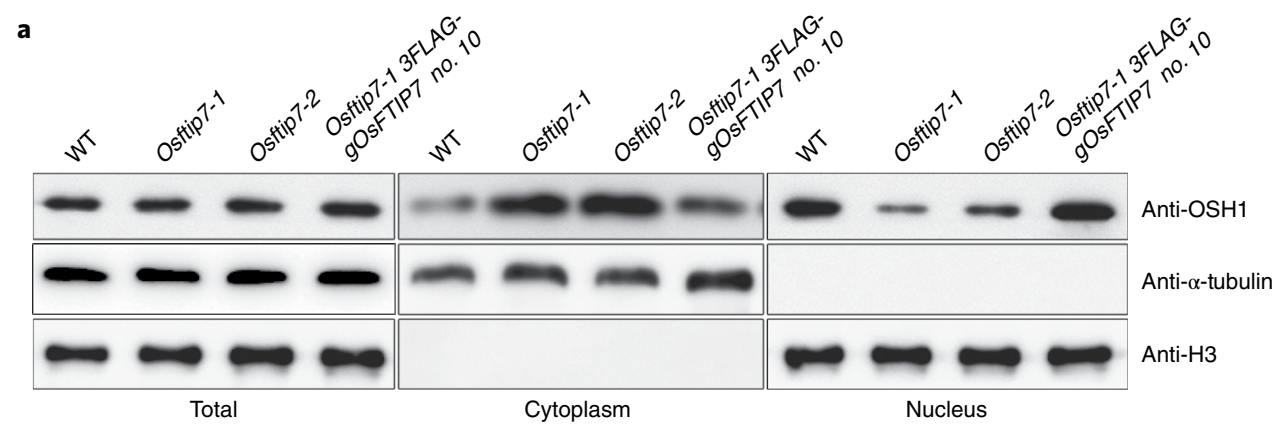

Fig. 6 | Original and Corrected.

Published online: 2 November 2018

https://doi.org/10.1038/s41477-018-0315-6 